\title{
For a Micro-Politics Analysis of Engineering Education
}

\author{
José Aravena-Reyes \\ Federal University of Juiz de Fora
}

\begin{abstract}
The idea that studies about education for engineers should be complemented with micro-politics analysis which is presented in this article. For such, we present a framework to conceptualizing micropolitics and some elements that show how the micro- and macro-politics are overlapped in any political fact. From this premise, the micro-politics is used to lift some elements of analysis of a particular case of engineering educational process in Brazil, where several dominant behaviors are characterized as violent or repressive behaviors that do not favor the development of technical inventivity, one of fundamental characteristics of the profession. What is argued here is that these behaviors are part of the range of a dominant subjectivity that has as its goal the maintenance of professional subjectivity not to develop in students a critical subjectivity, which must be produced under teaching techniques and pedagogical approaches. To consolidate the micro-politics analysis perspective are cited several statements used in Brazilian engineering education process, which diverts attention from the real reasons for failures in the engineers' education. Finally, a report of physics violence inside a Brazilian public institution is cited to illustrate how the coercive institutional power operates in the production of students' subjectivity.
\end{abstract}

Keywords: micro-politics, engineering education, subjectivity production

\section{Micro-Politics Re-Contextualizing the Educational Experience}

Apparently, micro-politics can be understood as a scale operation in relation to politics, in other words, as an operation that allows understanding politics in its micro dimension. Similarly, an operation that allows understanding macro dimension of politics would be macro-politics.

However, the concept of micro- or macro-politics would have to be thought of in terms of degrees of extension: micro being associated with small and macro associated with the big. But considering that this scaling operation can lead to set the proportion and the limits between the two terms, some considerations must be pointed out to show that the boundary between micro and macro is not as direct or related to extent as we might think. ${ }^{1}$

\subsection{Conceptual Framework for Micro-Politics Analysis}

The micro prefix suggests a small size. A small politics where political actions would be performed by a small number of actors whose effects also have repercussions on a scale is understood as small. Based on that, it might be thought that the domain of micro-politics is confined to this small collective policy.

Micro-politics as a discipline of study of small collective's political action incorporates a first difficulty if thought exclusively on the characteristic degree of extension that small collectives may show. This difficulty is

José Aravena-Reyes, DSc., Department of Civil Construction, Federal University of Juiz de Fora, Brazil; main research fields: Engineering Education, Engineering Philosophy, BIM, and Distance Education. Email: jose.aravena@ ufjf.edu.br. 
associated with the ability to identify what is produced or results from the action of small collectives versus what is produced or results from macro-political sphere. The second difficulty would be to analyze separately micro and macro policies; operation that can function as a strait-jacket that forces the analyst to separate a concrete political fact from two abstract perspectives, because the analytical process of a single concrete fact should be done exclusively from two conceptual categories.

Such difficulties arise with the distinction between micro and macro politics, because although the political fact is concrete and its actors are crossed by a multitude of other perspectives (historical, economic, aesthetic, etc.), the facts are separated in order to give sense to both abstract categories and thus become imperative to slice the original meaning to suit the requirement of analysis.

Another difficulty of understanding the micro-politics in terms of small collectives is that apparently, the effects of these actions should also be confined to the small collectives. However, thinking this way disregards the effects that micro-politics impacts on the sphere of macro-politics, as well as not incorporating the effects of macro-politics in the sphere of micro-politics results in a sterile procedure, since there is no way to distinguish a priori the effects of a sphere in the other. It would not be so easy, for example, to distinguish a priori which aspect of a given state policy affects a small collective without knowing the political setting of this small collective, as one could not infer a priori the macro-political effects from a small collective without knowing the reality of the other small collectives that form the social of the macro-politics action.

There is a condition of continuity between micro- and macro-politics that cannot be established based on the existence of two separate categories because the actors and effects of the political action are superimposed in one plot, where what can be attributed to the micro-politics crosses macro-politics and vice versa. In other words, the problem is not resolved by trying to establish external relationships that can arise between two ontologically different elements. ${ }^{2}$ There is integrity in the concrete political fact which loses dimensions of meaning each time that it is artificially sliced into two parts and then assembled in one artificially constructed totality.

Therefore, in this work, it is about pointing to the everyday and to observe the inventive processes in all its colorful update the understanding we have of collective experience. If on one hand we have the invention of daily life that takes the form of intensities that produce (or inhibit) the emergence of a fact, on the other, we have the stable representations in the form of conceptual categories that influence the context where the event arises.

Differently from what happens in the big cold categories of macro-politics, the focus here will be placed on the constitution of the collective experience, which obviously happens from both individual and collective political forces which act producing the conditions for the emergence of such an experience. And here, definitely the threshold between macro- and micro-politics is transposed by the figure of a plastic zone where the wide range of forces and individual and collective interests produces and updates on what we call everyday life.

In this direction, Gilles Deleuze and Félix Guattari (2006) made a great contribution to devoting a full chapter of the book A Thousand Plateaus to the topic, chapter which was titled "Micro-politics and Segmentarity."

More than hybridizing politics stating that all politics is at same time both macro- and micro-politics, the authors of this book presented the understanding of micro- and macro-politics in the form of a policy of segmentarities. 
The clippings of meaning that define the concepts - and also define the boundaries of their interrelationship — are understood as segments and assigned to the human a particular condition of being segmental, that is, of creating these segments, because it is in this way that the human being has operated in thought and life.

In everyday life, we live constantly in these segments, in which the human disintegrates himself to manage his operating as a living being, whether in the form of segments-things or segments-ways (or even in the form of coordination between them), that ultimately organizes the human living, individually and collectively.

It is interesting to understand that to Deleuze and Guattari, such segments have segmentation logics (mainly binary, linear, and circular ${ }^{3}$ ) that have traditionally given or taken grades of power and flexibility from humans to operate their own lives - without ones being completely separated from the others.

A flexible segment ensures its constituent forces in shaping the segmentarity from a multiplicity of sources of meaning, while a hard segmentarity makes it always echo the same centers of emanation of sense.

What defines a segmentarity is a broad set of relationships and dynamics and, in fact, that there are hard or flexible segmentarities is because there are differences of nature between them and also in their modes of operation. However, they coexist and even more, routinely pass from one to the other: Hard segments have flexible cores as soft segments also have hard core. Therefore, every human is both crossed by hard segmentarities - that the authors call molars - and flexible segmentarities — called molecular-and one or another predominates depending on the everyday circumstances and conditions.

The bureaucracy segment, for example, although molar, i.e., hard, hardly constituted and organized, embodies within a molecular inventiveness that breaks the rules established to circumvent the obstacles of bureaucratic rigidity. In the center of the molar nature of bureaucracy arises, also naturally, this molecular presence that induces a plastic or living dimension between the molar and the molecular of bureaucracy.

In the opposite direction, for example, before becoming a form of molar State, the National Socialist State is configured in the emergence of many small and different fascists who work in molecular cores and begin to gather strengths to form a single center of resonance from which it feeds its rigid and totalitarian molar condition.

\subsection{Micro-Politics and Engineering Education}

In this work, we are interested in higher education institutions, and as can be seen from the previous paragraph, there is certainly a condition of fascism that is constituted in the molecular relationships of state institutions as may be universities or schools, public or private, religious or secular, large or small, without the condition of they being under the tutelage of a totalitarian state. ${ }^{4}$

On the other hand, there is always something that escapes the totalizing interest: A fine line through which desire that does not fit or get exhausted in the established order, drains. There is always something out of order in the stability of the molar condition of the educational institution; there is always someone that causes instability and that ultimately is put in to check the whole petrified structure, its laws, its rules and consequently their way of inducing the dominant reality.

What we want to show in this work happens in the sphere of everyday teaching of engineers, where categories of the macro-politics (student, teacher, knowledge etc.) are intertwined in a network of interests so varied that it is impossible to understand the events without analyzing this tangle of trends in a language that includes all shades of the concrete life of its actors, where rigid categories don't give meaning to the events, but 
on the contrary, are the events - the very small events - that feed them and allow reframing the macro-politics descriptions because these latter operate always in trying to homogenize the everyday life, systematically disregarding their uniqueness and inventive wealth or replacing the wealth of the multiplicity of life for logics built under the terms of the abstract subjects of reason that do nothing more than help conserving existing structures of power.

The micro-politics issue (or better, the issue of the formations of desire in the social field analytics, according to Rolnik and Guattari 2010) is of interest, because the macro-political understanding of university is itself incomplete if one does not consider their conditions of production.

As will be argued here, in the specific case of engineering education, the professional's inventive power has been removed in such a way that results instigating to verify that much of that strength has been blocked in the formation process of engineering schools itself, a fact that makes it extremely relevant to the understanding of the role and meaning of the university, since this must be guided, among other equally important things, to the development of the conditions of autonomy of the members of a nation.

In the next section, we will expose an overview of the weaknesses in the Brazilian engineering educational practice that can shed some light around the need to expand the analysis of the educational process of engineers to some micro political aspects.

\section{Engineering and Technical Inventiveness}

This study would be meaningless if it does not show that it is urgent to change something in Brazilian engineering education. Something that could cause the abandonment of the passive role of simple operators on how is reproduced the dominant system to take an active role in driving political forces of technical inventiveness in order to reorient the inventive processes that give conditions for the emergence of other modes of existence. 5

In macro-political terms, all are apparently well thought out. Under Brazilian law, the issue of engineering education is formulated in the National Guidelines for Teaching Undergraduate Engineering in Brazil (MEC, 2002), where the understanding of what should be the engineer is described in the following text:

Article 3-The Undergraduate Engineering has as a profile of the egress grad/professional engineer with generalist, humanist, critical and reflective formation, able to absorb and develop new technologies, stimulating their creative and critical role in the identification and resolution of problems, considering its political, economic, social, environmental, and cultural aspects, with ethical and humanistic vision in meeting the demands of society. $(2002,1)$

In fact, the entire formulation described in the previous text should be guaranteed, in terms of attainment, through a pedagogical project: Article 5-Each engineering course should have a pedagogical project that clearly demonstrates how all the activities planned will ensure the desired profile of its egresses and the development of competencies and skills expected.

The rest of the guidelines document describes other skills and abilities to be developed by the egress, among which are those of "conceiving, designing, and analyzing systems, products, and processes" and "identify, formulate, and solve engineering problems."

The guidelines for engineering discriminate competencies and skills that should enable the development of technical inventiveness and, according to Article 5, it delegates to educational institutions, the responsibility of developing a (political) pedagogical project able to clearly materialize this possibility.

However, as Deleuze and Guattari (2010) reinforce, all politics is both macro and micro. 
There is a fundamental dimension related to the meaning emanating from the text of the guidelines and operates in an invisible sphere (the micro level), in the same way as the text itself embodies statements that must have arisen from small centers of emission of meaning, which at some moment become resonant until building its dominant sense (the macro-political sphere).

One of the hegemonic meanings in engineering is that it deals with the resolution of problems, though, as suggested here, one might think that engineering is the invention of other-and even new-types of existence through the design of their materials conditions.

It can be understood from the text of Article 3 that the statements "absorb and develop new technologies" and "the identification and resolution of problems" already describe how to configure the inventive dimension in engineering courses, but as this is not explicit, it gives margin to many interpretations. Even when it calls for the need for a critical and creative activity of students in the educational process, such creativity is apparently only related to the identification and resolution of problems. But in another part of the text of the guidelines (Art. 4, III) between skills and abilities to be developed in the engineer, the one to conceive, design, and analyze systems, products, and services, seems to bring more of the notion of inventiveness, but, with a small caveat: The technical inventiveness is not restricted to the understanding, language or rationality of systems (even less of the goods or services).

The inventiveness escapes all these closures, sets itself across as sense of inventive life and only takes the technical or systemic form when called to close itself in those areas, and not otherwise.

The subtle closure that promotes the technical inventiveness is a closure in its existential sense and this allows placing it under the control of something greater: the systems (pre-understanding of the reality) or the products and services (an economic ordering of the reality). In other words, technical inventiveness was subjugated to predefined objectives. Hence, it does not operate autonomously anymore; it will be the systems, products and services that will define what it can do.

Allied to this limit imposed on technical inventiveness, the idea of solving problems, even creatively, generates a perverse relationship of domination that sucks all the vitality of engineering to put it on the disposition of an unidentified being. In other words, if the task of the engineer is to solve problems, somewhere they should be enunciated.

The list of skills and abilities of the guidelines seem to dissolve the last question since it is considered necessary that the engineers know how to identify, formulate, and solve engineering problems (Art. 4, V).

However, the situation is identical to the previous one. Again the inventiveness potential to enunciate problems is subjected to a greater interest (in this case, the engineering). It seems clear that there is no mistake when controlling technical inventiveness through a logical process of identification and formulation, however, the necessary cut in terms of skills and abilities is useless because the inventive experience cannot be conditioned on the recognition that a given problem must be fully inserted a priori in the field of engineering for someone to be able to identify and formulate it. This, without considering that the process of formulating (the formula), always operates on known (or identifiable) elements for which it shall establish its true (and demonstrable) relations.

Engineering has always been associated with problem-solving, but the technical inventiveness is beyond this perspective. There is not a priori condition for a problem, even less to say that a problem is purely an engineering problem. Indeed, what is at stake is the very problem in its ontological condition. Before having 
been enunciated, a problem is no more than a sensitive state that manifests itself as a demand of displacement from the current reality.

In a basic text of "Introduction to Engineering" (Bazzo 1990), it can be seen that the notion of engineering as problem-solving is well rooted in the dominant thought about formative processes. In other words, according to the reasoning described here, from some time ago, the inventive processes of engineering are directed to obey to a productive logic external to the process of inventiveness of technical, itself.

From this perspective, we can understand that this dominant sense of engineering without autonomy, comes from an invisible dimension that has been operating in establishing a relationship of dependency between inventing and solving problems. Translating this thought without autonomy to within the engineering education, we could say that there is currently a production of a thought subjected to a doctrine that reduces the power of the inventive thinking to put it under the domain of operative interests of a cold and completely depersonalized socioeconomic machine, which takes advantage a formative process that does not even recognize conceptually the deep dimension of inventing that allows subtly to emasculate the inventive possibilities by using external statements that define a frame of practices under which are controlled and limited the natural movements of the curious and inventive minds of engineering students.

What we intend to show below is that, parallel to the neutralization of the technical inventiveness, there is a teaching practice in Brazilian schools of engineering that produces a subjectivity that actually favors better a dynamic of consolidation of the dominant socioeconomic model than a dynamic that promotes the emergence of conditions for the creation of new modes of existence through their material conditions.

Implicit (or micro-politic) demands of consolidation of the capitalist model subtly promote and legitimize, as part of the training process for professional life, a set of practices of domination, humiliation, and violence that seem to be necessary to produce a professional subjectivity subjected to dominant pattern of life. ${ }^{6}$

\section{Production of the Dominant Subjectivity in Engineering}

\subsection{University Hazing as a Device for Production of Subjectivity}

In Brazil, there is a traditional activity of initiation to college life organized by senior students to receive the freshmen. In this activity, the students entering either have to perform a sort of tasks and activities organized by veterans as a way to welcome to college life and promote the initial socialization of newcomers. This rite of passage has been the agenda of many controversies because recently it has been observed a prejudiced tone and an increase in the levels of violence exposure on the jokes made (Zuim 2011), a fact that has forced the university authority to control or inhibit such practices within the university campus.

A position of control or inhibition of these acts by the university authority undoubtedly exerts a strong influence on the levels of violence and humiliation present in the games. However, when looking deeper into the dynamics of the welcoming process, it is worrying to note that a series of sadistic and masochistic forms of violence, humiliation are still present in this rite of initiation into college life, showing that there is a dimension of the problem that is far from being equated only by control measures and discipline.

Indeed, the hazing of freshmen ${ }^{7}$ - as this rite of initialization in university life is called - does not manifest its bias of humiliation and violence only when it is materialized through the identification of a misconduct by some veteran who spent the limit tolerated, but when one observes that although sublimated in the form of a 
joke initiation to college life, the meaning of hazing can be understood as rising under the symbolic establishment of a hierarchical order against which nothing can be done.

In other words, more than a pure prank, the haze is a playful process of learning about the structures of violence and humiliation of college life and its main message can be summarized as: Have fun while you are living; have fun with domination and humiliation because they really exist.

From this reasoning, if the domination and humiliation are presented at the beginning of college life through a rite of passage, it is because it is important to understand from the beginning of college life that hazing is both a means of imposing the logic of submission of institutional power as a way of declaring the existence of violence and the abuse of power and privilege of the older: a food chain that creates and legitimizes the conditions for the maintenance of mechanisms of a perverse life in the name of an identity or a need of belonging to a social group, in this case, the social group of university. This structure of violence and humiliation puts on top of the power those who know and therefore cannot be questioned: the veterans. Indeed, if we consider that the university operates with mostly those who graduated in it (usually MSC and Ph.D. teachers within the university), the haze can be thought of as a kind of compulsory tradition to pass to the first degree of the structures of power and leaderships established inside the university campus - the first stage in the verticality of the structure of institutional power, which those who hold the knowledge are at the top of the organization (formal or informal) of power.

From this perspective, it should not cause estrangement to be argued in this paper that in the academy, there is, on various aspects, an evil machine that guarantees the maintenance of that power, including through practices that create conditions for the imposition and consolidation during the formative process, the reigning-dominant subjectivity that they will live in their professional life.

The case of Brazilian engineering education has particular nuances, but this does not mean that the same logic is not present in other sectors of university life. In fact, one could conclude that the university, as an institution established through coercive and violent means, the production process of the dominant subjectivity, is more conservative than it should (and is said to) be.

No doubts there are conditions of domination (and subversion) related to the disciplinary powers of university teachers as themselves, but there are some statements that are directly linked to the socio-educational context of engineering.

\subsection{Teacher Training in Engineering}

In any analysis of engineering education, it should be remembered that, traditionally, there is no didactic and pedagogical training for teachers of engineering courses in Brazil. Most teachers of engineering have no access to information about the appropriate values, methods, and educational techniques to the context of engineering education. Until now, it dominates the view that it is sufficient to have postgraduate diploma in engineering to act as a professional of higher education teaching in engineering. Most of the job openings for supply positions in engineering teaching of Brazilian public institutions do not require specific training in education for the candidates.

At this point, we should consider whether it is acceptable a situation where the skills of the professional engineer, still as a researcher, are the same that should be present in an engineering teacher, because in fact, there seems to be a tacit understanding that it is not necessary to be formally educated in any specific competences to the exercise of university teaching in engineering. 
Therefore, from the above, it can be understood that the dominant subjectivity of the professional engineer or researcher is exactly what determines the dominant subjectivity on the student formative process and not that such subjectivity is the result of an educational project built on theoretical foundations and practical relations of teaching and learning engineering, as it should be.

This analysis becomes essential because, if engineering school promotes a process of formation of the professional engineer, it is very important to know why such formation process produces as much dropout and repetition. In fact, it is also vital to know whether the questions used to solve this enigma have been adequately formulated.

In the next section, we propose approaches that arise from our micro-politics analysis and may shed some light on how, invisible to the macro-political indicators, certain production processes of subjectivity engineer are happening in the formative stages of the profession.

\section{False Problems in Engineer's Education}

There are a number of problems that are regularly mentioned as the main reasons for the failures of the Brazilian teaching-learning process of engineering, as well as actions are constantly made to solve them. The results of these actions are often disappointing or even come to be questioned due to the persistence of methods that cannot handle the education demanded by society (Oliveira \& Pereira 2012).

The persistence of the problems can be considered proportional to the persistence of its solutions because there is a kind of technical rationality that haunts many sectors of the technological area which can be summarized as a thought which values more the model of reality that it attempts to describe than the same reality from which the model appears. Specifically talking about Brazilian engineering education, this addiction does questioning reality as such and not the solutions that are presented for the problems that arise from it. The insistence of this way of thinking practically forces to understand reality as wrong, which causes a disincentive that installs itself as a feeling of powerlessness in a reality that does not want to be tamed by the model adopted.

In the case of engineering, it is necessary to question whether the statements of problems cited as a reason for the failures of the teaching-learning process are really the ones that should be pointed out, since the results show a certain exhaustion of these approaches.

In fact, one thing is to have a concern with teaching methodologies and another very different concern is to be aware of the reasons why the majority of the teaching community takes no action before a methodological problem. It is recurrent to present the problems of teaching as methodological problems, but it is uncommon presenting as the real problem the lack of interest of the faculty to adopt methodological alternative to traditional forms (the latter is already exhausted). False problems lead to concerns which do not attack the relevant causes of tension in a situation. We could say that there are several false problems in engineering education and from that, we could show that there are well-identified reasons that prevent establishing of consistent enunciates to deal with such problems. In the following sections, we will address some of the statements that direct our attention to aspects of process that proves itself inaccurate and often act as obstacles to approach them with the proper depth.

\subsection{The Methodological Issue}

One of the most common statements in engineering courses is associated with sole responsibility assigned to the student by the failure of the teaching and learning process. 
Indeed, it is very common for students to blame themselves for the poor performance in a given discipline, even if there is a set of evidences showing that the fault lies in the teaching and learning process but not in any unfavorable cognitive condition of the student.

In fact, often the evidence of failure of the training process is so great that it is difficult to understand why it have not yet been taken appropriate actions allowing to emphasize the foundations of the failures in the process, even less if such actions could come backed by perceptions of the students themselves.

From the macro-political perspective, this problem (again) seems to be solved when one observes that there are legal instruments that recognize the need for an evaluation of the faculty, including on the part of the student segment. However, statements like those that there is technical inability of students to evaluate their teachers are warmly defended by the teachers. It comes to the point of teachers who claim a certain state of disrespect-which is expressed as an improper questioning of authority-to configure a statement of class in order to prevent an evaluation of the teaching process by students. In some cases, during debates promoted by the students inside the university, professors have placed the issue of student evaluation in terms of disruption of a kind of tacit agreement of mutual tolerance for the misconduct of both segments. However, here there is nothing more than a mechanism of coercion, since, if broken by the student body, the pact of tolerance with teachers, a new evaluation form of the student performance (obviously loaded with an imaginary retaliation) will emerge as a result of new trusts.

It should be clear that in relation to teaching and learning, although there is a single process which sets the relationship of communication and language - as for the dimension of the learning as for teaching — we cannot infer from this that there is a horizontal condition of construction of meaning where students and teachers have the same prerogatives to create their space of perspectives and beliefs. A hard, methodological, and micro-political work is necessary to flatten out these power relations and ensure space for minimum autonomy so that the student can arise as apprentices and create their critical conditions because, in fact, there will always be a vertical power structure on top of which is the teacher.

Therefore, the evaluation effort of the teaching process, however good the intentions are, is going to always confront, not only with a teaching situation that merits review, but with all the established power structure.

On the analysis surface, the problem seems to be methodological. But it would not be appropriate to say that the problem is purely methodological without making reference to the fact that what should be attacked is the lack of appropriate teaching practice in the context of engineering. In other words, the political fault (and not methodological) is a resistance from the faculty to the adoption of appropriate practices to the formation process of the engineer, even as the law itself establishes (LDB, 1995).

With this, it is clear that on limiting the problem to the methodological issue, one escapes from the reflective scope the political conditions that allow it (or not) to be properly solved.

In practical terms, that teacher who takes a conservative attitude towards the adoption of innovative methodologies and technologies is not purely rising over a methodological technical statement which negates the need for such practices. By the opposite, he is arguing on this type of statement to become invisible a set of conditions for resistance to the loss of political power that these changes entail. The most obvious of all is the condition of being able to choose what to do with the time devoted to teaching life: for example, choose between, on the one hand, to take time to do the research they want, and on the other hand, to participate in a continued didactical-pedagogical updating program for the constant demands of education improvement. 


\subsection{The Cognitive Issue}

Another dominant enunciated in engineering schools reinforces the idea that much of the subject matter of engineering has a higher complexity than normal and that learning difficulties is inherent to the limited cognitive capacity of students.

Perhaps this is the most visible face of college conservatism, because beside delegating to the own set of information that must be mediated by teachers a condition of difficulty that they should equate themselves (and therefore make it easier), it is common understanding for teachers that it is the student who has (or not) adequate cognitive ability to understand the object of study mediated: i.e., what it produces as a form of mediation to the object of study (whether in the form of a lecture or a textual material) is perfectly designed so that any student, with minimal preparation and monitoring, should perform satisfactorily the tasks of appropriation of the syllabus.

This statement reveals a very important thing. In the university teaching career, the teacher is not relieved of responsibility to properly mediate access to the object of study, even having the autonomy to determine this process. That it is made from the understanding that, before the mediation process on screen, some students are better than others, such a teaching practice is sustained by a complex and somewhat useful epistemological question, because at the end all, it is to form an apprentice in particular and not an abstraction to which students are compared, revealing better or worse the model established.

From this point, a perverse mechanism of consolidation of power structures is regenerated, because the student with the best performance is always benefited at the expense of one who has more learning difficulties, allowing them to promote the production of a subjectivity that puts merit only in the result of a process where we leave aside all aspects that evaluate the effort of the student, posing as undeniable truth that the mediation process used by the teacher is adequate.

Certainly in macro-political terms (academic standards, curricula etc.), the directions and didactic concerns are well addressed. But it is exactly on the territory of everyday life within the teaching process, in the classroom, where teacher's behaviors emerge showing that humiliation is one way to keep this logic that hides the (in)efficiency of mediation, under a supposed (un)favorable natural condition to the teaching of engineering process. Each student failure, this condition of lack of cognitive ability is called to disqualify and drown out any possibility of criticism of teacher mediation process.

The picture is always nothing favorable to the student, since to the natural cognitive condition of these apprentices must be added the natural condition of difficulty in subjects called technical, factors that make the learning process in engineering program, naturally difficult. But what actually is not at issue in this statement is the difficulty (natural, we might say) of the teacher to be able to equate properly and efficiently the mediation process, a task which is his responsibility.

\subsection{The Issue of Objective and Practical Thinking}

It is not uncommon to hear that the formation of the engineer requires the development of an objective and practical thinking; however, it is not difficult to understand that this statement can be permeated by a reading that serves more to maintain under control the process of teaching than to promote the development of skills that gives objective and practical answers to the kind of problems the engineers deal with.

It has been a long time since, in the philosophy of science, objectivity is seen as necessary to the scientific and technological development, but not as the establishment of a truth condition (Maturana \& Varela 1990). 
The sociology of knowledge has constantly warned on the production conditions and the interests do not manifest that operate in the consolidation of science (Latour 2000). And those citations are not to expel the objectivity of engineer education, but to include it in the teaching process as a means to arrive at an understanding of the situations faced by engineers, but not as an end in itself.

In the tradition of engineering schools, objectivity is configured as an end in itself when it asks the learner to align with a particular thought and thus prevent him from fleeing to make inquiries about a kind of teaching process where everything must be thought of in terms of objectivity. No one can present the objectivity as a straitjacket (an end) that requires the learner to be objective at the expense of detaching of himself or of the questions and beliefs that he/she is elaborating. Promoting the objective being should not be a factor of disciplinary coercion to prevail technical-scientific reading of reality, mainly because it is not an absolute truth, but also because it promotes a submission to a state of affairs where someone-which he is not - has access to the absolute truth.

An objective condition that is taught as truth necessarily promotes an emptying of criticism and apprentice's discussion because there is no need to question what is taken as true, as there will be no reason to question the veracity of the statements of those who hold this knowledge, helping to consolidate the power structure associated with those who claim to know and, therefore, should not be questioned.

On the other hand, practical thinking that the institution tries to develop in the student is closer to training to execute (without questioning) a prior reading of reality than one kind of thinking that could be called effective, if we want to move in that perspective of practical thinking.

Being practical, in common sense, connotes a behavior where people act quickly without investing many analytical efforts towards a given situation. Whether for an emergency or any other aspect that motivates such behavior, one takes experience or tacit knowledge (and not the explicit knowledge) to respond to the situation where the student must be practical.

No doubt that common sense only collects what is visible in what we call practical, as well as much of practical being navigates in an area where being less analytical (or where the situation is less explicit) does not exempt the practical being of his/her responsibilities and the consequences of his/her actions. Therefore, it is very important that the practical being in engineering must be presented on very strong fundamentals, where there is no space to form a practical being disassociated to the inherent responsibility of his/her decisions.

The first question we should ask about the teachings of being practical in engineering is exploring how it materializes where, indeed, immediately lies a complex situation because there is no clarity of the teaching process of practical being, nor conceptual or methodological, which means that ultimately, in most cases, the learner should build his/her practical sense with very few signals from the teaching process, which leads to misunderstandings, misconceptions, or even obedience. ${ }^{8}$

The risk of this situation is that the practical being can be reduced to a simple obedient being, which, while not developed the practical being competence, a (practical) dependency around another being, admittedly practical (in this case, the teacher) is consolidated. The situation described is not helpful to the formation of the practical being, since the basic elements of practical thinking emanate from a complex appropriation of empirical knowledge, which requires a turning to yourself to develop a very personal relationship with the lived experience.

In fact, also it is not only about to induce the practical being by manipulating the concrete. That is not what we intend to teach as the practical engineer. Here lies another clarification: The practical is not running a 
concrete (or material) practice. Knowledge through concrete practice does not guarantee the formation of a particular way of approaching situations of professional life based on experience and tacit knowledge.

To be objective or practical cannot be "obedience" to any technical or scientific assumption nor to those who say they know how to operate in this mode. To be apprentice does not require such obedience to the teachings of the academy, but often is in this way that silences are imposed, questions are neutralized, subjectivities are punished, making the diversion route traced by the dominant thought the greatest enemy of the engineering student.

\subsection{The Issue of the Access to Favorable Socioeconomic Conditions.}

Another present element in the construction of collective statements by teachers is the relationship established between the profession and certain benefits that capitalist society gives access to.

Within the family, there is already tremendous pressure favoring the adoption of traditional ways of life of capitalist society. Students are induced very early to make career choices and, long before they have knowledge or experiences related to career choices, there prevails a certain vision that they will be happier if they enroll in programs that achieve favorable financial conditions. In this group, there are professions such as medicine, law, or engineering.

Throughout university life, this situation is strengthened. Teachers make this statement more than a tool to develop in students an interest in the classroom. They also use this statement as a coercive tool to prevent students from deviating from the path that must be followed for the success of this social group. There is a set of behaviors that are perceived as part of the repertoire of social life, policy, or moral that sustains the professional class and, obviously, that are considered by students as necessary references of the professional training.

The teacher is always in a power relationship in the teaching process and although it seems to be a simple consequence of the natural influence that the personal life of the teacher can have on students, in this power relationship, there is a significant lack of building other references to life in society. In a way, the social figure of teachers is the same for all, and for some reason, other forms of social behavior are not encouraged, leaving the student and all his insecurities about his economic future, the mercy of a single model of tranquility, which is obviously living a life of consumption and material achievement, accessible only through differentiated levels of economic gains.

We could say that a perverse relationship is established when associated a set of economic advantages to an artificially promoted effort to the teaching process of the teachers: Those who survive the hard training process will receive such economic benefits. Thus, thousands of alternative lives are completely canceled by the lack of statements from teachers in relation to these other possibilities of life, but also the advantaged class discourse suggests that all the troubles of the training process should be overcome from the expectations of redemption that material world offers to the graduated professional.

Many questions of the formation process cannot be addressed because of this reading that those students make about the economic future of the profession. For them, the condition of difficulty of learning the profession becomes true because of such reference of class: Such advantaged economic condition becomes, in fact, the real reward that society provides for its hard work in the training process.

Some additional considerations regard the socioeconomic level ascent, even by an understanding of this situation by a Darwinian logic from certain teachers. Some teachers point out that the failure of a significant 
number of students is required so that the best can continue to enjoy the gains of a structure with a low supply of professionals (which can be artificially constructed) that meets the (ever increasing) technical demands of society.

Hardly engineering professors provide statements concerning to possible engineer life that are outside from this socioeconomic projection of professional class. It is like a heresy to promote other forms of life associated with the profession; it is a kind of treason to their class to find professional achievements that point to a lifeless valued in terms of production of material wealth.

One does not graduate to live, but to live a life. Many students come to the university to discard their own desires because they do not find the necessary power to exploit them, being forced to resign with a unique possibility of life, imposed by force of the enunciations of the dominant hegemonic subjectivity spaces.

\section{Reports of Violence}

Apparently, the education of engineers is well done. But as mentioned before, this can be only true in the macro-political sphere. When you do a thorough examination of how it shapes the thinking of future professionals, it starts getting easier to understand that there is a project aimed at training an idea or a political vision of working life. Rather, there is a condition of professional life that seems like it should be ensured at any cost, through a training process where the humiliation and psychological violence play a key role in the production of dominant subjectivity.

To better understand this statement, this section will describe a real situation which exemplifies the violent institutional form that takes the everyday life of certain engineering schools. University life inside these schools consolidates a specific kind of subjectivity from the insistence on certain statements of the faculty (and often the student body itself) which, although they are not part of any dimension of training for engineering courses, they are present in ordinary statements that are made within the process of teaching and learning.

The following account would suggest that the way to consolidate the dominant professional subjectivity in the training process is based on two elements: the space of power of the engineer-teacher in the educational process and the use of coercion of challenging conduct to the current state of affairs as control procedure. In fact, as will be described later, the forms of coercion manifest more as natural events of the professional culture than as a misconduct of the role of university professor.

\subsection{A Report of Physical Violence}

We are watching, perplexed, the various phenomena of violence within the school environment that often are recognized as consequences of the educational model itself. The most violent episodes are attributed to abnormal or psychopathological behaviors, but there is a certain silent madness that alerts us that beneath the faces of normality of many good citizens, it has been silently building conditions of madness when they become visible, often arising in the form of violent crises (Leader 2013). Hence, it is permissible to ask around what (or who) feeds this silent madness. Do the institution and the formative process have some responsibility about it?

The concern here arises from a micro-analysis that may be unveiling the causes of increased stress experienced by students around the achievement of objectives of training imposed by an unclear rationale regarding the relevance of the objectives and based on a huge volume of demands in relation to time required for the appropriation of the content. 
Recently, for example, there was a report of an unprecedented incident of physical violence, where a student of an engineering course physically assaulted the teacher responsible for one of the subjects he was studying.

The episode, though unpublished, reveals the complex situation in which is the relationship between teachers and students from the Brazilian engineering schools. In fact, the exemplary punishment applied to the student shows the urgent need to control the situation efficiently and thus prevent new situations from arising.

According to reports gathered inside the college, it is possible to conclude that some of the events simply are not part of the analysis of the research process initiated to investigate the episode cited, since the act is investigated focused exclusively on the student's act of aggression.

No doubt the act of aggression is clearly characterized. The offender, during the investigative process, explains the situation as a consequence of a high state of stress that culminates in an outbreak of which he has no recollection about the episode.

From this argumentation, the committee formed by school teachers, is emphatic in applying the maximum punishment he could take in his realm of power: suspension of the student for a period of six months.

On the other hand, the teacher assaulted is at no time questioned about any element that could have contributed to the unfortunate situation. Such inquiries, although commonplace, become even more relevant due to that there are reports showing that the teacher himself has been the target of several complaints of harassment and little moral teaching behaviors through petitions presented to the school board and complaints from the students themselves in public ministry.

Focusing the analysis of the event described, the visible signs of the moment of the student aggression are an open manifestation of the understanding guided the investigative committee around what is violence: the visible fact of the aggressor. Emancipation and complaints of students regarding the embarrassing conduct of teacher assaulted are not enough to neutralize the space of enunciation of the academic power that obviously defends the teacher's action space in front of the potential danger that surrounds the practice of teaching. But, it is not part of the argumentation that the institution does nothing to prevent the natural clash of an oppressed student that, through a violent act, seeks its radical insubordination of a power that enjoys subtle mechanisms of oppression, theoretically required to the educational process.

On the contrary, the commission takes a historical view and does an exercise in rhetoric not to put in evidence the signs that could show in the investigative process the relationship of the violent incident to causes originated on the exercise of institutional power.

Before this episode, when asked later about the forms of humiliation they suffer, some report everyday situations, ranging from insults to acts of moral harassment, which are usually directly associated with the exercise of institutional power.

The theme of violence of the faculty is as complex as the corrective pat in the formation of the infant, however, if we contextualize the teaching violence to the engineering student training process, corrective action aimed at reoriented a deviation of a student conduct in relation to a process (said) learning, later will be adopted as a valid behavior within the repertoire of professional behavior.

In addition to the illustrative example cited earlier, the power of the faculty permeates so deeply the formation of the engineer that the silence face to the subtle forms of coercion and violence needs to be understood from the micro perspective, in other words, it is clearly necessary to develop an understanding of 
how is the configuration within the formative process of the engineers and the demonstrations of the flows of desire and the repression that accompany it.

From this transgressive reading, it is possible to alert about the invisible guidelines operating in the production of subjectivity of the engineering student, which are aimed at maintaining the current understanding of work life and to maintain under control the spaces which promote invention or transformation of these and other life possibilities.

\section{Conclusions}

Being a teacher in engineering courses is not limited to be an engineer. Also, being a teacher requires a thorough understanding about the social life and the role of the professional in it.

Such insights are so profound that they must be part of the teacher himself, to the point of understanding that they appear in every act of teaching life in their rational, natural, visceral, or thoughtless forms: More than an everyday life built under the terms of a teaching rhetoric, it is necessary to develop a set of behaviors beyond rationale: a teaching ethics.

The set of behaviors that would give basis for such teaching ethics necessarily require a broad reflection, not limited to macro-political categories, but on the contrary: By bringing micro-politics reflection of the educational act, the possibilities for understanding the teaching activity are expanded and enriched.

\section{Notes}

1. Rolnik (2006) writes "For everything we have said, it is unnecessary to point out that macro and micro, here, have absolutely nothing to do with 'big' (society, the State ... the whole) and 'small' (the individual, the intra-individual, the group ... the part, the unit)," 59.

2. As written by Abbagnano (2000, 662), ontology is a metaphysics concept that defines the doctrine that studies the fundamental characteristics of Being.

3. As examples of that we have: a binary segmentarity in the form of a cut between men and women; a circular segmentarity in the form of a radial direction given by my things-things in my neighborhood; and a linear segmentarity represented by the historical sequence family-school-Army.

4. In part, we also want to show in this paper that within an institution that is said democratic and former of citizens, there is the imposition of a dominant mode of life that operates through numerous micro-fascists, totalitarian and violent processes.

5. In this paper, we defend the idea that the technique responds to certain urgency to invent modes of existence from the design of their material conditions.

6. In describing the concept of Empire from Hardt \& Negri (2005), Peter Pal Pelbart (2011) writes: "The new regime of control ... is exercised through communication systems, information networks, mentoring activities, and it is as internalized and reactivated by the subjects, in what the authors call a state of autonomous alienation." Another part of the text presents: "Nowadays the power is not only repressive, restrictive, punitive, but it positively takes care of the production and reproduction of life itself in its entirety." 82.

7. "Trote" in Portuguese.

8. It is very common to students to receive orders such as "do as I say," "no time to philosophize about it."

\section{Works Cited}

Abbagnano, Nicola. Dictionary of Philosophy, 4a Edition. Brazil: Martins Fontes Editors, 2000.

Bazzo, Walter. Introduction to Engineering. Brazil: Sao Paulo State University Editors, 1990.

CNE/CES (Câmara Nacional de Educação). 11th Resolution of the National Chamber of Education: Set the National Curriculum Guidelines for Engineering Undergraduate Courses in Brazil. Brazil, Union Official Newspaper, 2002.

Deleuze, Gilles \& Guattari, Felix. A Thousand Plateaus: Capitalism and Schizophrenia, Chaper 9, Micropolitics and Segmentarity. Brazil: 34 Editors, 2006. 
Guattari, Felix \& Rolnik, Suely. Micropolitics: Cartographies of Desire, 10th Edition. Brazil: Vozes Editors, 2010.

Hardt, Michel \& Negri, Antoni. Multitude, War and Democracy in the Age of Empire. Brazil: Record Editors, 2005.

Latour, Bruno. Science in Action: How to Follow Scientist and Engineers Through Society. Brazil: Sao Paulo State University Editors, 2000.

Lei de Diretrizes, Básicas. Law of Basic Guidelines of Education. Ministry of Education. Brazil: Union Official Newspaper, 1995. Leader, Darian. What is Madness: Delirium and Health in Everyday's Life. Brazil: Jorgue Zahar Editors, 2013.

Maturana, Humberto \& Varela, Francisco. The Knowledge Tree: The Biological Basis for the Human Understanding, 4th Edition. Chile: University Editors, 1990.

Oliveira, Vanderli \& Pereira, Danilo. Reflexions About the Engineer-Teacher Practice, Proceeding of the XL Brazilian Congress of Engineering and Education. Brazil: Proceeding of the XL Brazilian Congress of Engineering and Education, 2012.

Pal Pelbart, Peter. Capital Life: Essay of Biopolitics. Brazil: Iluminuras Ltda Editors, 2003.

Rolnik, Suely. Sentimental Cartography: Contemporary Transformations of Desire, Cartographies Collection. Brazil: Federal University of Rio Grande do Sul Editors, 2006.

Zuim, Antonio. "The University Hazing as Spectacular Violence.” Education and Reality Vol. 36, No. 2. Brazil: Federal University of Rio Grande do Sul Editors, 2011. 